\title{
FREUD E AS NEUROCIÊNCIAS, UM DIÁLOGO CONTEMPORÂNEO
}

\author{
Wilza Vieira Villela ${ }^{1}$ \\ Universidade Federal de São Paulo, São Paulo-SP, Brasil
}

Por que retomar os escritos de Freud, em particular o "Projeto para uma psicologia científica" (1996b), que, escrito em 1895, foi rejeitado pelo autor e abandonado inconcluso e sem qualquer tipo de revisão, só vindo a público em 1950? Uma primeira resposta poderia ser a persistência do sofrimento humano, em que pese às diversas estratégias médicas, psicológicas, religiosas e outras para superá-lo e à sua constante atualização em manifestações tanto corporais quanto comportamentais ou da alma. Outra resposta possível apontaria o esforço de aproximação de diferentes campos do saber para a compreensão do fenômeno humano, uma das marcas da contemporaneidade. De fato, diante dos avanços da psicofarmacologia e da crescente descrição do sujeito como corporeidade, deslocando-se a ideia de um sujeito psicológico - que dominou a produção acadêmica da área ao longo do século $X X$-, é de saudar a iniciativa de Benilton Bezerra Junior em trazer a debate a leitura atualizada de uma obra que pode ser considerada seminal, no livro Projeto para uma psicologia científica: Freud $e$ as neurociências, Civilização Brasileira, RJ, 2013, 251p., que compõe a coleção "Para ler Freud", da mesma editora (também disponível em e-book).

A obra tem como objetivo apresentar as ideias de Freud sobre a articulação entre a neurologia e a psicopatologia, empreendimento que busca atender a seu interesse em construir uma psicologia que possa se dizer "científica" segundo os cânones de cientificidade da sua época. Segundo Benilton, a recuperação deste trabalho se justifica não apenas pela pertinência das hipóteses formuladas por Freud sobre as bases neurofisiológicas do funcionamento mental, algumas hoje confirmadas pelos estudos de neurociências, mas também como modo de contribuir para a redução do hiato que ainda existe entre as pesquisas no campo das neurociências e psicanálise.

Benilton demonstra que para Freud não havia ruptura entre corpo e alma, cérebro e mente, o biológico e o psíquico. O privilégio dado pelo seu trabalho posterior aos aspectos psicológicos deve-se mais às limitações técnicas existentes à época para um exame mais detalhado do funcionamento neural do que a alguma convicção.

Pela análise cuidadosa de uma ampla literatura, Benilton constrói seu argumento sobre a atualidade do "Projeto" num texto organizado em quatro capítulos substantivos.

No primeiro capítulo o texto de Freud é situado dentro da obra do autor, permitindo que o leitor tome contato com o entusiasmo de Freud no início da formulação de suas hipóteses e na sua posterior decepção, quando o estado do conhecimento científico e dos meios laboratoriais disponíveis impediram 0 avanço da sua pesquisa. Foi esta decepção que o levou a rejeitar o manuscrito, só recuperado pela intuição e persistência de Marie Bonaparte em impedir sua destruição, como Freud desejava.

No segundo capítulo são apresentadas as contribuições de Freud à neurologia anteriores à criação da psicanálise. Pela recuperação de textos pouco conhecidos, percebe-se que, desde os primórdios de seu trabalho, o médico e pesquisador Freud já se interrogava sobre as

1 Endereço para correspondência: Rua Aroaba, 482, ap. 64A, Vila Leopoldina, CEP 053.150-21 - São Paulo-SP, Brasil. E-mail: wilza.vi@terra.com.br. 
relações entre o corpo biológico e as emoções, e as condições de possibilidade de constituição de um sujeito singular a partir de uma base neurofisiológica relativamente indiferenciada. Contrariando grande parte dos colegas neurologistas da época, os quais explicavam as ações do sistema nervoso a partir do modelo do arco reflexo e das teorias localizacionistas, Freud propugnava uma organização mais complexa, regulada pela busca de homeostase.

As ideias que Freud explora no "Projeto", escrito logo após "Estudos sobre a Histeria" (1996a), são apresentadas de modo resumido no terceiro capítulo. Para vencer o desafio de tornar claras as intricadas hipóteses esboçadas no "Projeto", Benilton destaca as inquietações que orientam a investigação freudiana neste trabalho - a dinâmica de regulação da quantidade do impulso e sua descarga e a transformação das quantidades de impulsos em qualidades de respostas. Cabe destaque tanto às propostas freudianas sobre o funcionamento neural, as quais hoje encontram ressonância nos estudos neurocientíficos, quanto às que servirão de base para o posterior desenvolvimento da psicanálise, quando não é mais possível prosseguir o estudo numa perspectiva integrativa. Como exemplos podem-se citar as formulações sobre dor e prazer como organizadores da vida anímica e da atividade neuronal, sobre a existência de processos primários e secundários como etapas distintas do funcionamento mental, e sobre as relações entre pensamento, linguagem e sonhos. Para Benilton, embora o "Projeto" seja o rascunho de uma obra inacabada, considerado por alguns a despedida do Freud neurologista ou um conjunto de metáforas para a psicanálise, seu objetivo de buscar substratos neurofisiológicos que explicassem as situações observadas na clínica, conciliando descrições psicológicas e neurológicas, é mais atual que nunca.

Este comentário é confirmado no quarto e último capítulo, no qual são discutidas as tendências atuais da investigação neurocientífica e suas aproximações com as ideias de Freud. Inicialmente Benilton analisa a tensão que ao longo do século $\mathrm{XX}$ envolveu os pesquisadores do campo da neurologia e da psicanálise, parcialmente explicável pela forte oposição entre ciências da natureza e as ciências do humano que domina a produção do conhecimento no século $X X$, situação que só começa a se modificar a partir dos aos 90, quando se torna hegemônica a premissa de que não existe uma "natureza" intocada pela intervenção/experiência humana e de que a experiência humana é continuamente modelada pelo substrato material, a corporeidade do sujeito que a vivencia, a qual é continuamente transformada pela interação com o meio externo e com os outros. A evidência das múltiplas possibilidades de os sujeitos modificarem seus modos de pensar e sentir em função da atuação de substâncias químicas em seus cérebros mina a crença na possibilidade de uma disjunção entre o natural e o humano. Ao mesmo tempo, a demonstração da plasticidade neuronal e das modificações das redes sinápticas em função das experiências do sujeito inaugura uma nova vertente para a compreensão da "arquitetura funcional da mente" (p. 188), objeto último tanto da psicanálise quanto das neurociências. Tratase, assim, de reconhecer a reciprocidade entre os avanços em quaisquer dos campos. O mapeamento dos caminhos trilhados a partir desta abertura para o diálogo, que finaliza o capítulo e o livro, é bastante ilustrativo, com destaque para a referência ao trabalho de Antonio Damásio, bastante conhecido internacionalmente e do público brasileiro, que de forma contínua e consistente tem buscado estabelecer as conexões entre cérebro e mente, na perspectiva de que esta se deriva do corpo, e não do cérebro, e de que, embora os estados mentais não existam sem a presença de estados físicos correlatos, um não se reduz ao outro, por haver diferença de propriedades entre ambos. Tal perspectiva está próxima à que Freud defendia no "Projeto", ao propor a existência de grupos de neurônios com propriedades distintas, relativas à quantidade ou qualidade dos estímulos e respostas homeostáticas.

O convite feito por Benilton para uma reelaboração do entendimento da obra freudiana a partir do reconhecimento da investigação iniciada no "Projeto" como uma etapa fundamental na construção da psicanálise é instigante, e provoca o leitor a se inserir no diálogo entre esta e a neurociência não como juiz de uma disputa, e sim, como alguém que busca os melhores encaixes entre peças de um complicado quebra-cabeça.

Benilton Jr é psiquiatra e psicanalista, idealizador e pesquisador do Programa de Estudos e Pesquisas da Ação e do Sujeito (PEPPAS), vinculado ao Programa de Pós 
Graduação em Saúde Coletiva do Instituto de Medicina Social da UERJ.

\section{REFERÊNCIAS}

Bezerra Junior, B. (2013). Projeto para uma psicologia científica: Freud e as neurociências, Rio de Janeiro: Civilização Brasileira.

Freud, S. (1996a). Estudos sobre a Histeria. In J. Strachey (Ed. e J. Salomão, Trad.), Edição Standard Brasileira das obras psicológicas completas de Sigmund Freud. (Vol. 2). Rio de Janeiro: Imago. (Original publicado em 18931895).
Freud, S. (1996b). Projeto para uma Psicologia Científica. In J. Strachey (Ed. e J. Salomão, Trad.), Edição Standard Brasileira das obras psicológicas completas de Sigmund Freud. (Vol. 1, pp. 335-454). Rio de Janeiro: Imago. (Original publicado em 1895).

Recebido em 24/05/2014 Aceito em 07/08/2014

Wilza Vieira Villela: médica psiquiatra, livre-docente em Ciências Humanas e Sociais em Saúde, Departamento de Medicina Preventiva, Escola Paulista de Medicina, Universidade Federal de São Paulo, Brasil. 